\title{
Discussion Group: Teaching and learning using the www
}

\author{
Ernie Jordan, \\ $W G$ (Bill) Hewett
}

\begin{abstract}
This paper presents a report of a discussion group that was focused on the issues concerning teaching and learning using the world wide web. Three sessions were held, together with a formal reporting session. The sessions took distinctly different, but complementary, paths that covered a wide range of topics. The first role of this paper is to report the actual discussions of the group and then to try to synthesise the discussions into a form that is more accessible. The conclusions represent more a consciousness-raising agenda rather than guidelines for the optimal installation of web facilities.
\end{abstract}

IT Education, Internet, www

\section{Keywords}

\section{INTRODUCTION}

The initial aims of the discussion group were modest enough:

- To identify where each discussion group participant was located on the continuum of use and understanding of the emerging technologies commonly referred to as the Internet and the World Wide Web (www),

- To identify common problems that had been experienced,

- To uncover new opportunities, either for the individual participants or for groups working together,

- To develop potential directions for future efforts.

Three sessions were held, with the issues facing the group being introduced at each session. The titles and summaries for the sessions were developed after the event, after reflection on the activities and discussions of the sessions. The first session was extremely active as participants discussed the many issues that were simultaneously driving and impeding the development of the use of the web for teaching and learning. This was summarised as the essential paradoxes / forces at work in web development.

The second session was business like and technology driven, identifying the wide range of capabilities that were unique or distinctive about the web. This enabled the participants to identify things that could now be done better than before, as well as new capabilities. In the third session the participants reached into their rich experiences as teachers and learners to identify the high points and moments of significance. We then attempted to remap those 
experiences to the potential of the web, so that it would be a step toward teaching and learning excellence.

The conclusions represent the attempt to synthesise this fervent activity into something that is accessible to those who were not participants, the majority of the readers of this paper. Continuing discussion with the authors and participants is suggested in the conclusions, with the possibility of this being web-based.

\section{SESSION ONE - IDENTIFYING THE FORCES AND THE PARADOXES.}

\subsection{The Chair's opening comments:}

Macquarie Graduate School of Management used the www to publish a Home Page aimed at distributing publicity material for the MBA. More recently the School has attempted to use www for some time in teaching using the www tools rather than necessarily using the Internet. A pilot team of four people (academic, clerical and technical support) was established to explore teaching and learning using the www. This group was able to support one another and able to transfer skills as they developed. They identified a widespread effect on students but noted that things were slow to change. Simple loading of Powerpoint slides into web pages did not add much value to teaching, however loading up review questions was one simple way to move towards individual progress measurement.

Prior to this pilot there was little or no electronic communication between students and staff. This development seemed to encourage off campus access and communication but the teaching approach remained face to face. The students were enthusiastic about the new resource but still came to class. The team extended the pilot to include a "chat room" for students to work together on problems. The results of the experiment were presented to staff who were mostly "technophobes". Most were interested but did not particularly wish to become involved or to take the development further. Thus there is a need to do something to bring others along.

\subsection{General discussion:}

There was some discussion on one implementation of the the acceptance of assignment submissions from students. This is done by having them set up their own home pages and directing assessors to the material from this initial source. The problem of student cheating was raised and discussed. It was pointed out that the problem was not really greater under this emerging technology, it only appeared so. Furthermore, several members pointed out that emerging software would make detection of plagiarism, etc. much simpler.

The possibility of web based case studies was raised. It was felt that a live case could be developed which used the technology. Students could be given segments of the case as and when it was appropriate much more easily than on the paper based approaches. It was pointed out that the opportunity for academics to develop cases in combination with academics at other universities was much greater using the www technology. The possibility of a "global" team working on a single case study was raised. 
The question was asked that perhaps to get real advantage, students could go to live pages and extract up to the minute examples from the web. Two comments were made as a result of this discussion. Firstly it was observed that the main information on the www that reflected live company information was advertising and marketing material which was not of significant use in live study (except in marketing units, etc.). The second point made was that in many teaching and learning situations one did not want up to the minute details but some specific details which properly illustrate a point. The example given was to use the latest data from the stock exchange might send quite the wrong message. To illustrate some issues one might best structure the data from say the late 1980s.

Problems of the availability, reliability and ownership/management of the underpinning technology was raised. The possibility of unleashing a class of students onto the same web page at the same time would lead to an impractical response time. Members raised the need to have local caching of material to be used. This raised the clear differences between the availability and management of the technology in various institutions.

The twin issues of control over the technology and the independence of the resources will have a different impact on different classes of use and different study areas. For example, it was pointed out that the study of geography in many places depended on large amounts of www based data, satellite pictures, and so on, that are now readily available.

In summary it was agreed that academics need some control over the environment. Clearly there will be a requirement for a culture shift in some institutions and some conflict will arise. The most significant conflict which must be discussed and addressed is the conflict which arises when the cost of the use of this new resource will be allocated: How will the cost be allocated? This question is especially significant when students are directed to access www resources around the world. This issue also raises problems of student equity which could occupy a discussion group itself.

It was recommended that the approach of allocating students a base amount of hours paid for by the institution and leaving them to pay for any excess, be adopted. The probable cost of around \$2 per hour was assumed in Australia and it was felt that 8-10 hours would serve most students in a particular unit of study. It was also pointed out that in the near future, many if not most students would have high bandwidth access to the internet, at their own cost, provided by local service providers.

The discussion ranged widely in this cost allocation area with the constant theme being the problem of allocating costs back to students which were previously born by institutions. Some concern was expressed that the focus of the technology would shift to cost saving to address the financial problems of institutions rather than the potential to radically alter the methods used by students and academics in the learning and teaching process. This issue was dealt with eventually in the third session.

Concern was also expressed that many institutions will not be able to increase their capacity at a satisfactory rate to be able to handle the traffic expected in the near future. Present pilot studies which have proved successful may not be able to be 'ramped up' to 'production volumes'. The number of possible hits on academic home pages may bring existing facilities to their knees. The example of Georgia State University was raised. Georgia State were struggling to provide an adequate service to students on an increasing budget of around US $\$ 500,000$ pa. A service provider (MCI) offered to take on the responsibility of providing student access and transfer the costs to the student. The estimated revenue flow to MCI has recently reached US\$16 million. The need to examine the 
ethical/moral/political issue of this cost transfer was raised and discussed in some detail with no clear conclusion being reached.

The need to differentiate between "education" and "edutainment" was identified as another potential pitfall. We need to concentrate on whether this new technology provides or makes possible something which cannot be provided under the traditional model. This was eventually dealt with in the second session. It was noted that not everybody would have simple and cheap access to the internet and the internet did not reach everywhere. Producing the real possibility of an information rich and information poor split with an underclass of the people without access.

The ownership issue of material published on www was briefly discussed. It was emphasised that this issue will have a profound impact on the use of the web as a educational tool. The observation was made that the www is open to everybody and that this has both positive and negative implications. However, it was felt that this "open-to-everybody" aspect needs to be the underpinning issue explored since unless this brings value there is no particular merit in the tools.

We cannot expect significant gains if we simply use the www to teach in the same way as we have done traditionally. This technology cuts across space and time. The question to be asked in analysing if this new technology had something to bring to the table was: Is it better than a book? What are the things we get from the web software that add value. Things such as linkages are important. Smooth links to additional resources often in differing media. Because of the www, the hyper link tools are becoming mature and widely available. Links to video and diagrams are now practical.

The comment was made that the web should be viewed as simply another information source. This led to discussions on the quality of the information and the need to prepare students to search the web and to filter it for quality information. The following question was raised: Can the technology be used to deliver savings and educational richness through group work not previously possible?

The problems of access and confidence with the technology will disappear as today's children enter the educational system.

The next issue concerned training. It was agreed that faculty members must be trained in the use of the technology, but how can this be done most effectively? Moreover, how can we justify the training costs and how can we justify other resource costs such as server space and power?

In summary we have a connectivity and usage paradox. The www can be a wonderful resource but who pays? Questions we need to ask are:

- Are we getting benefits?

- Is there some objective way of measuring the results?

- Are we doing things better?

- How can we ensure people do not get carried away with the technology?

The issue of using this technology to reassess the ways people are learning was raised. The concept of student centred learning was discussed and the impact this technology might have on student centred learning. Delivering education is no longer linear. This technology enables us to break the sequential step-by-step approach and allows the educator to be transformed into a guide/ mentor/ facilitator.

We need new approaches to ascertain just what value we can add for the student. 


\subsection{Summary}

The discussion group clearly felt that there were some great possibilities for the use of the www in teaching and learning. However their organisational experience had 'wised them up' to the facts that there were others whose approaches to the technology would not be driven by the quality of the teaching and learning that was made possible. There are many forces at work, often the strongest is the need to reduce costs in the teaching delivery area. The discussion was summarised in terms of a set of paradoxes and issues at work in the further application of the web to teaching and learning. For each force there were apparent contradictions: getting cheaper may cost more, for example. So we have summarised the discussions in terms of the essential paradoxes:

- connectivity

- structure / openness

- richness

- currency / timeliness

- teamwork / cooperation

\subsection{Connectivity}

The www enables connection to everyone, everywhere, but at what cost and who pays? The suggestion that we can have rich connectivity may only be if we are already (financially) rich. If we use this rich connectivity too much we may end up poor!

\subsection{Structure and openness}

The web is open, unstructured, individually interactive but students need and expect us to structure knowledge for them. In that sense we can pose a "TV test": Is it better than TV? Television presents an enormous amount of information but it is usually the job of the viewer to structure and organise it.

\subsection{Richness}

The web offers a rich array of information about organisations and individuals but quality may be lacking; you can get lost, not see the tree for the forest. To this end we put a "book test": Is it better than a book? Universities have extensive library facilities that already contain more knowledge than any of us is ever likely to comprehend. Having an even bigger library, in and of itself does not lead to "better" learning.

\subsection{Currency / timeliness}

On the www information is potentially up-to-the-minute, real time and instantaneous but 'natural' time may not lead to the best learning experiences. Case studies and data from well known and well studied situations may be the preferred learning vehicle. Thus a critical question is: Is being up to the minute of any value in the particular course that I am teaching? 


\subsection{Teamwork / cooperation}

With the www we can work with virtual groups all over the world but an individual student is more likely to follow his/her own path. The individual sitting in front of a PC (or network computer) is more likely to 'do their own thing' than engage in a potentially richer group activity. The barriers to working with groups are quite high in some cultures. There is also a gap between the potential of group work and the achievable group work, due principally to the limitations of available group software. Furthermore a question we need to ask is: Are we facilitating groups or teams? We assume that teams will achieve more through their skill sharing and agreed objectives. A group may be no more focused than the set of passengers on a bus.

\section{SESSION TWO - TECHNOLOGY DRIVEN}

\subsection{Introduction}

The first session had revealed that many factors affect what is to be developed for the web. This revealed an enormous depth of feeling, especially among participants whose organisations systematically exploited technology for cost savings with little consideration for enhancement. In the second session it was seen to be important to be able to move on to other issues. It was possible to focus on technology driven possibilities by posing the key questions:

- What can we do with the technology?

- What is new and different?

However, many of the issues raised in the first session were still alive and well. Thus discussion items appeared that are not strictly under this heading. They are reported here because the context lends some additional information to the reader.

\subsection{General discussion}

When the TV was initially developed it was proposed that it would revolutionise teaching. Education was thought to be its only possible use. Are people similarly thinking that the www will deliver all things to all people? The www can be used for more effective teaching. The tool enables a less sequential presentation, a clear improvement over presentation tools like Powerpoint. We must search for innovative ways to prepare and to get students to do more that they would in the past.

What we must begin to examine and circulate are:

- Teaching \& learning approaches that seem to differ

- Examples and methods used

- New models of learning

Privacy issues were raised and the example of students rebelling at photographs appearing on the web was raised. In the past photographs had been taken and placed on the wall. This new technology makes simple the mass distribution of personal details never previously thought about. 
Questions were raised about the locus of control of teaching and learning, because of the web allowing students to disappear off into their own individual line of investigation:

- Does the educator have control over the sites accessed?

- How does the educator follow up on just what the student is doing?

- Does the teacher tell the student what to do or let them do what they like?

- How is the student effort evaluated?

However, putting a different perspective to this, the question was asked : When you send your students to the library do you watch what they read?

Additional relevant comments were that we have lost the control previously exercised by the librarian regarding the quality and reliability of the library contents. Furthermore, when you wish your students to be shown how to use the library resources, you simply arrange for them to visit the appropriate person in the library. How do you get your students to be given the equivalent exposure on how to effectively and efficiently access and use the resources available on the web? How will students be taught to screen what they are reading? Issues of censorship, filtering and quality of information sources came up in this discussion.

The simplicity of publication on the web was seen to be at the same time a benefit and a problem, an additional paradox to those of the first session.

We need to get back to the two basic questions:

- What does the web do?

- How does the web impact what we do?

\subsection{Examples of how the web has changed things:}

- There are universities already up and running on the web, delivering course units or even whole programs through web based facilities.

- Students are already spending a lot of time on the web, is it constructive? Are we guiding them or following them?

- ISWorld (http://www.isworld.org/isworld.html) discussion groups offer many pointers to what is being done. We do not have to invent all the techniques ourselves, we can learn from each other and with each other.

- ISWorld has references to a lot of teaching material already in place on the web. Many IS educators have placed substantial amounts of teaching material on their web pages, making it available for widespread use.

- The quality of what people are teaching has already been improved because of the rich availability of other people's work. Teaching is improving because of this sharing.

- Students can be pointed at richer material to review at their leisure.

The distribution of material clearly worries many people. The copyright issues and quality issues are yet to be resolved. However, the fact is that the material is already there and the amount is steadily growing.

The observation was agreed that the web is neutral. It is NOT time bound. We are now able to teach in an asynchronous mode. This is a hidden benefit not realised by many until they experience it for themselves. However, we must ask: Is "asynchronous teaching" a new 
term? Is it a new experience? References may be found in work covering the Groupware and Group Decision Support Systems.

The web provides another way for people with a common interest to get together. For example the Journal of Reflection on Teaching published an electronic edition recently. Five or six articles were made available on the web. The rich discussion which followed in the following weeks covered ground which would have taken years under the traditional publication and review approach.

We need to think carefully about what we need face to face meetings and teaching for. We need to ensure that this important and often expensive experience is used for its optimum purpose. We need to address the question What things must be done face to face?

Questions to be addressed are :

- What is the most appropriate time to use the technology? Is there a place for use of the web in face to face teaching?

- What things can we do now that we could not do before?

- Are our students covering the ground faster than us?

- Do we need to encourage people to experiment and have fun for a while before we ask them to disseminate their findings?

What is the social cost of the web? Access seems to be limited. The majority of publications on the web are in English. Although there is a significant Japanese presence on the www and there appears to be an emerging phenomenon of "click here for the (German, Finish, French) version".

Does the hypertext and multi-media power add to presentations? The notion of an "open border" is one of the web's distinguishing features. It is a "drill down" environment and also a "drill out" environment. Its very flexibility means that people are tempted to start a process and take a "let's see what we get when we get there" approach. Is this necessarily good or bad?

\subsection{Summary}

The main activity in the second session was the examination of new possibilities opened up by the nature of the technology itself. However some of the issues of the first session were briefly revisited and issues that came to dominate the third session also emerged. Here we summarise only the examples of opportunities we felt were opened by this emerging technology. That is: what is there that we can now do with www, that we wanted to but couldn't do before; that is new or original, or that we can do much better?

Technology driven examples:

- shared teaching resources across the world - it is easy to publish and distribute material in this form; it is readily accessible anywhere in the world; several teachers can work together building resources that are easily shared;

- very large case studies that the student explores; a one-hundred page printed case study would be seen as overwhelming by most students, but a similar amount of material made available on the web is not immediately perceived to be a single, dominating document;

- very rich case studies - multimedia is easily incorporated into www; this allows a greater range of material to be incorporated into teaching materials; 
- asynchronous teaching, with the ability to escape from the time boundaries imposed by formal classroom settings;

- the unboundedness of the web leads to a potentially much richer student experience where they are able to take some control over the depth and direction of their study.

\section{SESSION THREE - TOWARDS TEACHING \& LEARNING EXCELLENCE}

This session was conducted as a brainstorming session. The initial task was to isolate as many issues as possible that come to mind when we think about good teaching and learning experiences. The second objective, having identified the key elements in teaching and learning, was to look at the potential for the emerging www and internet technologies and identify opportunities to extend and support traditional teaching excellence. Those teaching and learning outcomes that most closely matched with web technologies were grouped into three broad categories or dimensions:

- openness,

- participation and

- imagination.

\subsection{Openness}

This refers to learning experiences that are divergent, that facilitate extension into new areas, that encourage exploration and remove boundaries. Key words and phrases in this area and the web responses are shown in the following table.

$\begin{array}{ll}\text { Key words and key phrases } & \text { Web response } \\ \text { I never thought of it like that } & \begin{array}{l}\text { Learning rather than a teaching technology. } \\ \text { Teachers must prepare the material well or the learning opportunity will be lost. }\end{array} \\ \text { Hunger for more } & \begin{array}{l}\text { Satisfying to use } \\ \text { Multiple resources } \\ \text { Open and suited for more use } \\ \text { and More \& More \& More }\end{array} \\ \text { Open Ended } & \begin{array}{l}\text { Democratic, new form of publishing } \\ \text { The web is by design an Information Repository } \\ \text { Continually changing. Details may not be the same tomorrow. }\end{array} \\ \text { Freeing from Prejudice } & \begin{array}{l}\text { Open access } \\ \text { Genderless communication } \\ \text { Wide range of views }\end{array} \\ \text { cAlways Open" unlike the library } \\ \text { Timely }\end{array}$




\subsection{Participation}

This refers to learning experiences where the student becomes active, a participant, able to put their own attitudes and knowledge into the situation. Key words and phrases in this area and the web responses are shown in the following table.

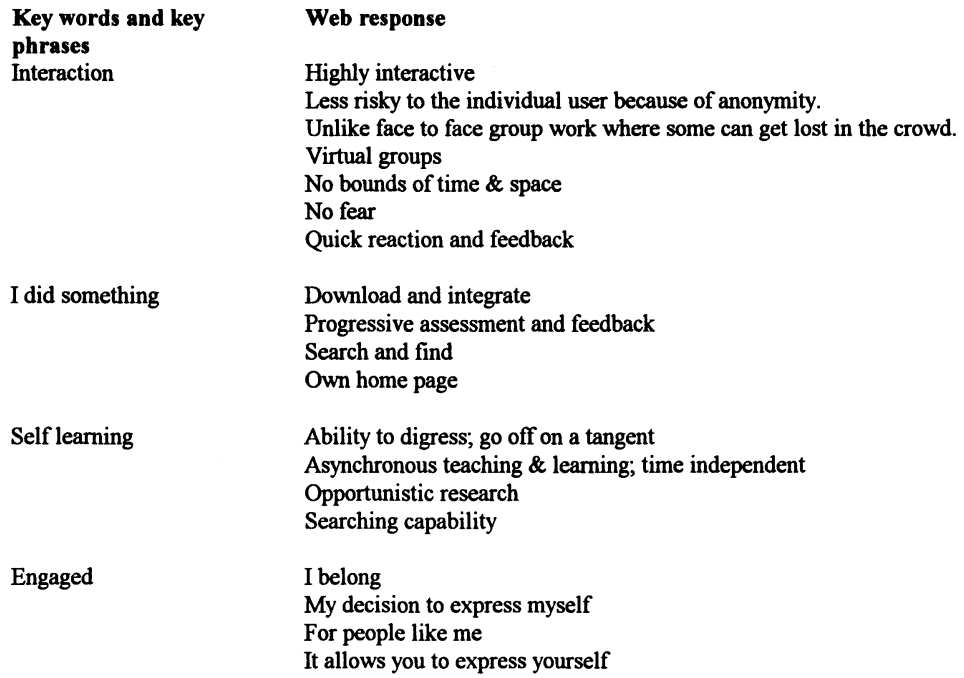

Self learning

Ability to digress; go off on a tangent

Asynchronous teaching \& learning; time independent

Opportunistic research

Searching capability

Engaged I belong

My decision to express myself

For people like me

It allows you to express yourself

\subsection{Imagination}

This refers to learning experiences where the student is extending their own powers of imagination and creativity into their learning - extending their own realities and giving new reflections. Key words and phrases in this area and the web responses are shown in the following table.

$\begin{array}{ll}\begin{array}{l}\text { Key words and key phrases } \\ \text { Real in their life }\end{array} & \begin{array}{l}\text { Web response } \\ \text { Allows students to choose related to their own interest! }\end{array} \\ \text { Stillness } & \begin{array}{l}\text { One on one feedback } \\ \text { Engaged more } \\ \text { "wonder" }\end{array} \\ \text { Performance } & \begin{array}{l}\text { Sophisticated, major resource } \\ \text { The web performs in itself } \\ \text { Sound and vision } \\ \text { More technology to entertain with. }\end{array} \\ \text { "one world"; firing the imagination } \\ \text { Integration } & \begin{array}{l}\text { Multimedia, contemporary technology } \\ \text { flexibility, ease of interface }\end{array} \\ \text { appropriate } & \begin{array}{l}\text { appropriate technology for the age } \\ \text { "Their Technology" }\end{array}\end{array}$


The web can be seen as the "people's palace of culture and learning" for today, in the way that the public library system used to be. We can be challenging students to bring what they find back so we can help them differentiate what is real from rubbish. If the student is bringing things back to class for comment this opens the opportunity for the educator to act as a mentor. The perennial concerns about delivering a good learning experience are still with us but we have new ways to address them.

We need to view the balance between teaching and learning. With this technology we can and indeed must be more involved. The teacher can/must structure the experience. Perhaps we are empowering students to learn with no obvious bounds, whereas a book by its very structure has bounds.

In the immediate future and in particular in the long term the notion of library support for education must change. There are far more resources available now via this emerging technology than via the traditional library. The skills of the librarian must not be lost. We must find a way to involve the librarian in the 'loop'. The traditional librarian was seen as a facilitator but also acted as a limiter. We require a new form of facilitator, a person skilled at finding and structuring information, but above all at attesting to the quality of information and information sources. Students must be given skills on how to use the new technology and information sources in the correct way. Publishers must be encouraged to make innovative use of the technology available.

The analogy used in describing this need was that of desktop publishing. The emergence of this technology seemed to devalue the skills of the traditional printer, in particular the layout designer. Everybody was suddenly capable of producing "print ready" text - but much of it was of inferior quality. Today the need for more sophisticated education in page layout, font selection, etc. is clear and accepted.

Electronic mail to authors from readers is a new 'power'. In the past, engaging an author in discussion might have taken many months and might well have been a fruitless exercise. Under the new technologies we find readers are as a matter of course engaging authors in discussion over email and receiving useful feedback on questions of clarification.

\subsection{Summary}

Even the material given above is only a summary of the discussion that took place. The overall finding was that there are many opportunities to use the web to engage students in more enriching learning experiences and that the students now have the ability more effectively to plan and decide on their own learning paths.

\section{OPPORTUNITIES FOR FURTHER DISCUSSION AND WORK}

There will be many new issues to investigate in the application of the technology and problems to be overcome along the way. More thought needs to go into preparing people who will be looking for things on the web. Additionally, more work needs to be done on educating people in preparing material for the web.

The change in the role of the library within the university was also highlighted as an area in which further thought and analysis were needed. Libraries have traditionally offered material that is 'approved' or 'acceptable' - so that students are able to take the material as a 
reliable basis. For the web we have a different situation, and students will need to be able to make those judgements - about the quality of material - for themselves.

\title{
6 PARTICIPANTS IN THE DISCUSSION GROUP:
}

\author{
Arthur Tatnall \\ Barbara Tatnall \\ Tony Greenwood \\ Alan Underwood \\ Connie Fulmer \\ Fumihiko Kamijo \\ J. Barrie Thompson \\ Ben Zion Barta \\ Frederick P Frank \\ Bill Davey \\ Peter Lawrence \\ Gregor Kuhlmann
}

